\title{
Reconstrucción de la memoria histórica y desarrollo del tejido social en comunidades Afrodescendientes
}

\section{Reconstruction of the historical memory and development of the social tissue in Afro- descendant communities}

\author{
DOI: http://dx.doi.org/10.17981/cultedusoc.12.1.2021.08
}

Enviado: 16 de abril de 2020 Aceptado 20 de agosto de 2020 Publicado: 1 de diciembre de 2020

\author{
Amparo Judith Echeverri-Arias \\ Universidad del Magdalena. Santa Marta (Colombia) \\ aecheverry@unimagdalena.edu.co \\ Michael Fabián Hernández-Bolívar \\ Universidad del Magdalena. Santa Marta (Colombia) \\ michaelhdez19@gmail.com
}

Para citar este artículo:

Echeverri-Arias, A. y Hernández-Bolívar, M. (2021). Reconstrucción de la memoria histórica y desarrollo del tejido social en comunidades Afrodescendientes. Cultura, Educación y Sociedad, 12(1), 119-132. DOI: http://dx.doi.org/10.17981/cultedusoc.12.1.2021.08

\section{Resumen}

El propósito del artículo es analizar la influencia de la reconstrucción de la memoria histórica en comunidades afrodescendientes víctimas del conflicto armado sobre el desarrollo de tejido social, dentro del contexto afrocolombiano Benkos, localizados en la comunidad de Cristo Rey, Santa Marta, Colombia. Se realizó un estudio de corte cualitativo, utilizando la entrevista, observación directa y grupos focales como técnicas de recolección y procesamiento de información, el análisis de contenido como técnica de interpretación de textos y software Atlas Ti para el análisis de los datos. Se trabajó con muestra compuesta por (12) doce familias durante aproximadamente un año calendario. Los resultados evidencian que aun cuando persisten injusticias sociales y falta de reconocimiento de los derechos ciudadanos por parte del Estado, la comunidad afrocolombiana ha encontrado mecanismos sociales de supervivencia en donde realzan y transmiten sus tradiciones, logrando fortalecer así su identidad como cultura creando espacios de intercambio para reconstruir la historia de sus vidas mediante el reconocimiento de su dignidad. Así mismo, muestran ser resilientes a las diferentes coyunturas sociales que enfrentan en su nuevo contexto, llegando a entenderlas y eventualmente iniciar un cambio, esto mediante la gestión de procesos de reparación simbólica y la generación y/o reconocimiento de nuevas estrategias de afrontamiento.

Palabras clave: Reconocimiento; tejido social; memoria histórica; afrodescendiente; historia

\section{Abstract}

The purpose of the article is to analyze the influence of the reconstruction of historical memory in Afrodescendant communities victims of the armed conflict on the development of the social tissues, within the Afro-Colombian context Benkos, located in the community of Cristo Rey, Santa Marta, Colombia. A qualitative study was carried out, using the interview, direct observation and focus groups as information gathering and processing techniques, content analysis as a text interpretation technique and Atlas Ti software for data analysis. We worked with a sample composed of (12) twelve families during approximately one calendar year. The results show that even when social injustices persist and the lack of recognition of citizen rights by the State, the Afro-Colombian community has found social survival mechanisms where they enhance and transmit their traditions, thus strengthening their identity as a culture by creating spaces for exchange. to reconstruct the story of their lives by recognizing their dignity. Likewise, they show to be resilient to the different social situations they face in their new context, coming to understand them and eventually initiate a change, this through the management of symbolic repair processes and the generation and / or recognition of new coping strategies.

Keywords: Recognition; social tissues; historical memory; people of African descent; history 


\section{INTRODUCCIÓN}

En la actualidad, la reconstrucción de la memoria histórica hace parte de las apuestas que el gobierno nacional fomenta e impulsa en aquellas comunidades históricamente afectadas por el conflicto armado como compromiso desde lo acordado en el primer proceso de paz exitoso dentro de Colombia, es por ello, que en comunidades afrocolombianas cuyos derechos han sido vulnerados en el marco del conflicto armado, la reconstrucción del tejido social y la nueva generación de prácticas y tradiciones, se conciben necesarias para su estudio.

Por tal motivo, la permanente recuperación de la memoria se entiende, no solo como una lucha cultural, sino también, se presenta como una batalla por el restablecimiento de sus derechos políticos., además de ello, la revisión sistemática de información (Todorov, 2012; Martínez, 2015; Grueso, 2010; Jaramillo, 2010; Lara, Enciso, Culma y González, 2017; Rueda, 2013), que corrobora la importancia de trabajar por la restitución de sus derechos humanos, resignificando como primer paso las experiencias negativas asociadas al conflicto, así como la necesidad imperativa de hacer a estos grupos étnicos participes de su propio cambio, toma la reconstrucción de la memoria histórica como una herramienta reparadora que impulse el desarrollo de su tejido comunitario, con esta iniciativa comunitaria se busca el empoderamiento de las comunidades afrocolombianas sobre su identidad, cultura, territorio y tejido social.

\section{REVISIÓN DE LITERATURA}

En Colombia, el conflicto armado se ha caracterizado por ser el cúmulo de sucesos que a lo largo de los años ha representado múltiples rostros de violencia reflejando un panorama de guerra y tensión permanente en cada uno de los rincones del Estado colombiano. Dicho panorama ha mostrado una imagen desalentadora e inhumana cargada de violaciones hacia los derechos humanos afectando indiscriminadamente cada uno de los estratos sociales, en especial aquellas poblaciones en situación de vulnerabilidad que hasta el día de hoy aún se desconoce el impacto de la tragedia en las distintas esferas sociales.

Las comunidades afrocolombianas, en continuos llamados desde el enfoque político, han propuesto al Estado y a la sociedad en general la necesidad de hacer valer sus voces desde su componente histórico, marcado inicialmente por la esclavización, a partir de allí se han centrado en la búsqueda de la construcción de paz que les faciliten, no solo reparar los perjuicios ocasionados por actos victimizantes durante el desarrollo del conflicto armado, sino a su vez, restablecer los niveles de cohesión histórica que conduzca a la desestigmatización de siglos de opresión, darle un renombre a la memoria y los territorios, y de esta forma acabar con los vicios históricos que han mantenido los ciclos de violencia cultural y simbólica (Martínez, 2015).

Todorov (2002) explica desde una perspectiva psicosocial la importancia de comprender la memoria del pasado y la conexión existente con el tejido social; para el autor es indispensable la reparación por la ofensa sufrida no desde la demanda del daño sino para "estar alerta sobre situaciones nuevas y sin embargo análogas; ya que advierte sobre el uso totalitario de la memoria y sus peligros, para señalar que su elogio incondicional se vuelve problemático" 
(p. 44). Del mismo modo, al momento de referir sobre la construcción de los hechos y del sentido otorgado desde la experiencia para las personas y comunidades enfocados en el trabajo de la rememoración. Todorov (2002) resalta dos elementos fundamentales descritos a continuación, el primero de ellos hace mención al lugar y el tiempo, es decir "el lugar de la memoria y el tiempo del pasado tampoco son los mismos en las diferentes esferas que componen nuestra vida social, sino que participan en configuraciones diferentes" (p. 19). Por otra parte, el segundo elemento hace referencia al buen uso de la memoria o recuperación del pasado, lo cual "no significa que el pasado deba regir el presente, sino que, al contrario, éste hará del pasado el uso que prefiera” (p. 25).

Por tanto resulta pertinente abordar los procesos de paz y de acercamiento a comunidades vulneradas porque van desarrollando movimientos de continuos racionamientos como sujetos de derechos individuales y colectivos, a su vez permiten un cambio en la concepción simbólica e interpretación desde sus antecedentes, pasando por su permanencia como esclavos, la abolición de la esclavitud y su reconocimiento como ciudadanos dentro del Estado colombiano, que los sitúa en la necesidad de comprender las subjetividades que los caracterizan en esta época, ahora como partícipes, sujetos de derechos y como población que ha sido víctima de hechos del conflicto armado colombiano y que se encaminan a la reconstrucción de su memoria para fortalecer su identidad de cultura histórica y aportar a la construcción de capital social (Grueso, 2010).

Ahora bien, en lo que concierne al trabajo con las comunidades en el proceso de la reconstrucción y reparación del tejido social, es necesario tener en cuenta que las secuelas del conflicto armado generan en las comunidades una huella que destruye por completo la autosostenibilidad de un grupo humano en general, ya que ante lo denigrante de la violencia se realiza una cosificación de lo humano a través de los actos de masacres y asesinatos que en últimas repercuten en otros grandes flagelos de índole social como la marginación, la desigualdad social y la pobreza (Jaramillo, 2010).

Para el mismo autor (Jaramillo, 2010), todo termina siendo una mezcla de múltiples factores que perduran en el tiempo dada la poca efectividad del gobierno colombiano en dar soluciones estratégicas que permitan la atención a dichas problemáticas, de igual forma y pese a algunos intentos "no oficiales" por recuperar la historia y la memoria de la violencia, siempre ha existido una memoria y una historia del pasado reciente que aparentemente han funcionado dentro del sistema institucional colombiano, incluso frente a la muy debatida democracia que ha caracterizado al sistema político del país. No obstante, es evidente como la resistencia política y la movilización social de diferentes sectores sociales, como son las víctimas organizadas que desde hace tiempo defienden y fortalecen sus memorias pasadas, transformando sus formas hegemónicas de memoria.

Sin embargo, el flagelo del conflicto armado ha resultado parte fundamental para el estudio de la historia socio-política de Colombia ya que a lo largo de los diferentes periodos de violencia por los que el país ha transitado el conflicto interno ha dejado como saldo un sinfín de personas afectadas directa e indirectamente por las múltiples consecuencias de la guerra. Cabe resaltar que la reparación del tejido social se realiza con víctimas del conflicto armado rescatando así la importancia de los procesos de reparación del tejido social y derecho a la verdad que han ocurrido a lo largo y ancho del país, esto gracias a la puesta en escena de políticas que favorecen la distinción de una identidad propia que se ve 
atribuida a la capacidad de contar con las garantías de no repetición y, consecuentemente contribuir a la generación de competencias y liderazgos de las propias regiones.

Por todo lo anterior, es de vital importancia la construcción y reconstrucción de la memoria histórica, pues en la medida que se realicen estos ejercicios, no solo se permitirá conocer un pasado y raíces, sino que también se hará participe a la comunidad de un proceso en común que permitirá el desarrollo de estrategias psicosociales enfocadas a la reparación del tejido social. Además, la recuperación, conservación, fortalecimiento y difusión de la memoria hace que las fronteras de las comunidades se extiendan hacia beneficios comunes (Pierre citado en Centro de Memoria, Paz y Reconciliación, s.f.).

\section{MetodoloGía}

El presente estudio se rige bajo el paradigma de la investigación cualitativa, el cual apunta a la comprensión de la realidad como parte de un proceso histórico de construcción a partir de la lógica de diversos actores sociales, analizando en profundidad sus costumbres y destacando su firma distintiva y las particularidades dignas de sus procesos sociales (Latorre, 2005). El diseño empleado fue de tipo fenomenológico, a razón de corresponder principalmente a dos razones, el primero centrado a que la investigación fenomenológica "trata de comprender los fenómenos a partir del sentido que adquieren las cosas para los individuos en el marco de su proyecto de mundo donde se originan" (Monje, 2011, p. 12) y por tal motivo se ajusta al propósito del proyecto investigativo, partiendo del significado que le otorgan los participantes en cuanto a la reconstrucción de su memoria histórica, en segundo lugar, responde a los intereses de los investigadores ya que para el tipo de población que se estudia, se hace necesario conocer y cuestionar la verdadera naturaleza de los fenómenos sociales que han ocurrido alrededor de la comunidad afrodescendiente, para posteriormente explicar los significados que surgen a raíz de la inmersión de su experiencia en determinado contexto social, cultural y político.

Ahora bien, el enfoque fenomenológico se enfoca en "explicar los significados en los que estamos inmersos en nuestra vida cotidiana, y no las relaciones estadísticas a partir de una serie de variables, el predominio de tales o cuales opiniones sociales, o la frecuencia de algunos comportamientos" (Rodríguez, Gill y García citados por Monje. 2011, p. 40). Es idóneo para la presente investigación pues el diseño fenomenológico se centra en el análisis de discursos y temas específicos, así como en la búsqueda de sus posibles significados, y el propósito del proyecto impera en estrategias narrativas, relacionadas a la reconstrucción de la memoria histórica, a su vez de contextualizar sus diferentes dinámicas que han mantenido, en términos de temporalidad (tiempo en que sucedieron), espacios (lugar en el cual ocurrieron), participación (las personas físicas que la vieron) y el contexto relacional (los lazos que se generaron durante las experiencias).

\section{Población}

Los actores fueron seleccionados a través del muestreo no probabilístico por conveniencia, donde son escogidos por criterio del investigador, sus características de proximidad y accesibilidad y así dar cumplimiento con el fin investigativo definido (Otzen y Manterola, 
2017). En paralelo a lo anterior, resulta pertinente aclarar que dicho tipo de muestreo en un estudio fenomenológico les permite a los investigadores comprender de manera holística la sucesión de fenómenos y procesos sociales según su complejidad, porque las preguntas que se plantean giran en torno al significado que los sujetos tienen. Por eso, es de primordial importancia el lugar que los participantes ocupan dentro del contexto social, cultural e histórico del que forman parte (Martínez-Salgado, 2012). En este caso resulta pertinente ya que permitió dar respuesta y objetividad al fin de los investigadores.

Ahora bien, se aclara que los entrevistados pertenecientes a las 12 familias son personas que se dedican al trabajo independiente en su mayoría en actividades de pesca y oficios varios, de estrato bajo medio y con un núcleo familiar bastante marcado dominado por el hombre en su mayoría. Los criterios que primaron para la escogencia de los actores fueron principalmente dos, el primero de ellos, la disposición de las familias en contar su historia debido a que no todos los participantes veían la oportunidad de reabrir nuevamente heridas del pasado violento que habían sido sometidos y estigmatizados y el segundo criterio fue el interés de algunos miembros de las familias en alzar su voz y crear esos espacios de memoria histórica en donde se sintieran escuchados e importantes mostrando sus raíces y recreando su cultura afrocolombiana.

Cabe resaltar, que durante los diferentes espacios destinados a recrear situaciones que permitieran la reconstrucción de su memoria histórica y por ende el desarrollo de su tejido social participaban diferentes miembros de una sola familia, en donde predominó el relato de la madre, el padre y los abuelos, esto permitió a los investigadores poder conocer a profundidad el impacto de sus formas de afrontar y narrar la historia en los diferentes aspectos de la vida de los entrevistados, ya que mientras para algunos les era difícil recordar y hablar del tema para otros los encuentros eran un método de escape a su realidad y una manera de sanar y reconstruir su tejido social.

\section{Método de investigación}

El método de investigación es de corte descriptivo-analítico ya que sus categorías están definidas bajo la identificación y descripción de características esenciales, como hechos o fenómenos que enmarcan la memoria de las víctimas (Latorre, 2005).

\section{Técnicas de recolección}

Las técnicas e instrumentos de recolección de información implementadas para el desarrollo del presente estudio fue en primer lugar la entrevista semiestructurada, ya que esta facilita la recolección de información por parte de sus participantes, mediante un conjunto de preguntas abiertas formuladas en un especifico orden, es decir, un protocolo o guion previamente elaborado (Mayan, 2001).

En segundo lugar, se hizo uso de la observación directa para analizar las relaciones sociales y dinámicas interpersonales de las diferentes personas pertenecientes a la comunidad afrodescendiente localizada en el barrio Cristo Rey de la ciudad de Santa Marta (Colombia). Por último y no menos importante para completar el análisis de la información se recolectaron historias de vida de los participantes, mediante técnicas de entrevistas 
y grupos focales, ya que a raíz del relato de su experiencia personal ayudaron a la definición de categorías, puesto que a partir del análisis sus realidades se logró precisar sus necesidades y permitió abordar las temáticas a tratar dentro de los diferentes grupos, dirigiéndolos hacia el empoderamiento de sus habilidades mediante la reconstrucción de su memoria histórica y el tejido social afectado por las diferentes facetas del conflicto armado.

\section{Metodología de análisis}

Se utilizó el análisis de contenido como técnica de interpretación de textos escritos (Bernete, 2013) y el software Atlas Ti para el análisis de los datos, permitiendo entonces la codificación, categorización y la respectiva lectura de la información desglosada (Varguillas, 2006; San Martín, 2014).

\section{RESULTADOS Y DISCUSIÓN}

A partir de la recolección de información que fue obtenida con la aplicación de diferentes técnicas de investigación, se establecen las siguientes categorías y subcategorías, permitiendo un análisis organizado de las categorías abordadas durante el proceso de investigación. Tal como se observa en la Tabla 1.

TABla 1.

Presentación de categorías y subcategorías.

\begin{tabular}{ll}
\hline \multicolumn{1}{c}{ Categorías } & \multicolumn{1}{c}{ Subcategorías } \\
\hline \multirow{2}{*}{ Memoria Histórica } & Percepción. \\
& Reconstrucción de memoria histórica \\
Tejido Social & Reparación social \\
Víctimas del Conflicto Armado & Desplazamiento forzado \\
& Huellas psicoafectivas \\
\hline
\end{tabular}

Fuente: Elaboración propia.

A partir de la narrativa de los entrevistados se elaboraron tres categorías principales, la primera de ellas conocida como memoria histórica, la segunda como tejido social y la tercera denominada víctima del conflicto armado; se procedió a la descripción del fenómeno explorado en relación a los lineamientos planteados en el proyecto de investigación, cada una conformada por subcategorías, tal como se detalla a continuación,

La categoría de memoria histórica está conformada por las subcategorías percepción y reconstrucción de memoria histórica. Con relación a la primera subcategoría de percepción, los entrevistados expresan variedad de conceptos relacionados con lo que entienden sobre la memoria histórica, por ejemplo, señalan:

Es la forma en como uno asume lo que le paso, eso doloroso que se sintió para no volver a sentirlo (Sujeto 3). 
Es recordar lo que viviste y que ya no te duela como antes" (sujeto 8), "pienso que eso es la manera en cómo uno maneja los recuerdos para que no sean tan traumáticos y ayuden a superar lo vivido (Sujeto 4).

Con base a lo anterior, Herrera (citado por Lara et al., 2017) menciona la pedagogía social de la memoria histórica como herramienta para abordar "desde las distintas prácticas de enseñanza formales e informales, historias temporales, referenciales, etc., la enseñanza sobre el dolor, el padecimiento, la esperanza y las condiciones de exigibilidad de derechos a la justicia y la reparación" (p. 42), los entrevistados van construyendo su percepción a raíz de las distintas experiencias surgidas en relación como víctimas del conflicto armado, en el presente caso se observa que la mayoría de la población ha sido partícipe previamente de ejercicios de reparación social a cargo de distintas entidades del gobierno, por lo que tienen conocimiento de los espacios y talleres de vivencias significativas, sin embargo, se pudo constatar que la mayoría de ellos presentan una revictimización de su experiencia por lo que dificulta un nuevo aprendizaje de resignificación de los hechos vividos.

Con respecto a la segunda subcategoría llamada reconstrucción de memoria histórica, los entrevistados expresaron diversas modalidades adoptadas para la realización de dicho ejercicio, tales como:

La verdad no he pensado en eso, concentrándose en el futuro de uno y de los hijos de uno, porque no sé qué más se puede hacer (Sujeto 6),

Me ha tocado duro, lo que siempre trato de hacer es olvidar, es alejar de mi mente esos pensamientos, pero es muy difícil, cuando un pensamiento sobre eso viene lo que hago es como huir de ellos...Trabajar en conjunto, nosotros como afros debemos ser valientes y saber que la vida siempre va a ser difícil e injusta, pero hay que saber vivir con eso (Sujeto 10).

En este orden de ideas, Rueda (2013) plantea que el fin último de la reconstrucción de la memoria histórica es que "las víctimas comprendan la realidad histórica que han vivido, razonen acerca de su pasado y contribuyan a la construcción del futuro como actores protagónicos de la sociedad del presente.” (p. 42), lo cual, y según el discurso de los participantes se logra evidenciar la carencia de estrategias de afrontamiento y de herramientas psicosociales que permitan en primera instancia rememorar desde una posición crítica y prospectiva para lograr la superación del pasado, recordado como evento traumático y doloroso, con aras de generar espacios de acción colectivas enfocados a la reivindicación de derechos.

Ahora bien, la categoría de tejido social está conformada por la subcategoría de reparación social. Los entrevistados mencionan no sentirse completamente reparados y la mayoría de ellos muestran cierta resistencia y desconfianza frente a los procesos de restauración de derechos, a pesar de participar en distintos talleres del gobierno y de haber realizado las denuncias y descargos correspondientes para ser reconocidos como víctimas, esto concuerda con lo analizado por Echavarria e Hinestroza (2016), quienes mencionan en su revisión que "todavía no se han materializado medidas que tiendan a reparar colectivamente a las comunidades negras en Colombia. El solo reconocimiento como sujeto de reparación no basta, se requiere que las medidas contempladas en el Decreto Ley 4635 (2011) sean una realidad palpable para las comunidades negras" (p. 9). 
Por otra parte, y como aspecto positivo la mayoría de ellos tiene presente que la unión como comunidad afro y la búsqueda de estrategias deben realizarse partiendo desde su realidad como desplazados y teniendo en cuenta la solución progresiva de sus necesidades, detallados a continuación:

No sé, porque uno en el momento se siente bien, acompañado, pero después del tiempo se vuelve a sentir igual, es algo difícil, por ende, nos toca ser buenos todos, los unos con los otros... Nosotros los afros somos personas humildes, y entre nosotros nos ayudamos mucho, creo que eso nos ha permitido poder seguir adelante como comunidad (Sujeto 9).

$\mathrm{Si}$, así tienen en cuenta lo que uno dice, y eso es importante, escuchar las voces de las personas que vivimos todos esos momentos horribles, lo importante es unirnos todos, que cuando la alcaldía venga o fundaciones vengan a ayudar, les colaboremos, participemos y podamos mejorar nuestra comunidad juntos (Sujeto 15).

En consecuencia, para Lizarazo (2014) hay un papel importante que han desarrollado las víctimas y que ha resultado fundamental a la hora de realizar reparación social, y esto no solo dentro del proceso de reconocimiento y restablecimiento de sus derechos, sino también al involucrarse activamente dentro de esos procesos de participación colectiva, donde declaran los hechos que realmente han ocurrido en su componente histórico, así como la ejecución de estrategias, aun a pesar de las dificultades que han sobrellevado desde hace mucho tiempo, haciendo énfasis en la no garantía y a la poca efectividad de los mecanismos de protección a víctimas y testigos.

En contraste con lo expuesto, tomando como base el relato de los entrevistados, hacen falta estrategias y acciones más eficaces y efectivas que contribuyan integralmente a la reparación del tejido social, ya que según lo encontrado por los investigadores, la mayoría de ellos denotan una desesperanza alrededor de su condición de vulnerabilidad acompañada de pobreza y exclusión social acompañada a su vez por una revictimización de lo ocurrido, por lo que urge una mayor lectura de análisis a la hora de trabajar con dichas comunidades violentadas históricamente.

Lo anterior es soportado por el análisis hecho por Prada y Noreña (2015), donde se describe que:

Las comunidades afro que vivencian el desplazamiento, reportan dificultades para acceder a la educación, empleo, salud, recreo, alimentación, entre otros derechos, lo que les ha llevado a salir de sus sitios de permanencias a las grandes ciudades, permitiendo una desculturización y una pérdida de identidad como pueblo, olvidando su esencia, ya que con 50 años de conflicto, las generaciones de estas poblaciones se han visto obligadas a desarrollarse en contextos social, cultural e históricamente diferentes a los de sus ancestros, olvidado su lengua, costumbres y ritos $(p, 13)$.

Este análisis es sustentando también por Morales (2018), donde menciona que factores subyacentes al conflicto, también introducida por los decretos-ley para comunidades étnicas, hace referencia a coyunturas políticas, sociales y económicas que han determinado, y continúan determinando aún hoy, la particular intensidad del conflicto armado en los territorios ancestrales, develando las complejas operaciones de estigmatización, discriminación e invisibilizarían de los pueblos étnicos, centrales en la intensidad particular con la que han sufrido históricamente el conflicto. En dicho análisis, también se reconoce la 
revictimización en la que permanecen las comunidades étnicas, en complicidad del Estado y su olvido sistemático.

De igual forma y según estudios realizados por Martín-Baro, Beristain, Calvo y Rodríguez (citados por Canal, Navarro y Camargo, 2015) la fractura del tejido social en comunidades que no han logrado ser reparadas desde un enfoque diferencial y de género suelen presentar con el paso del tiempo mayores flagelos sociales que desencadenan problemáticas generales, es decir, cuando los individuos que componen estas comunidades presentan cambios continuos de pareja, dentro de su actividad económica, el no continuar su escolaridad; incursionar en bandas criminales, cambiando su posición de víctimas a victimarios; el practicar el consumo de alcohol y drogas; asentarse en espacios de depresión económica y/o con fuerte presencia de grupos que fomentan la violencia y recurrencia de conflictos en la comunidad, por mencionar algunos.

Finalmente, la categoría de víctima del conflicto armado está conformada por las subcategorías desplazamiento forzado y huellas psicoafectivas. En consonancia con la primera subcategoría de la variable, los participantes describieron en sus relatos las experiencias relacionadas a este hecho victimizante, por ejemplo, dentro de las historias narradas, se describían los siguientes escenarios violentos:

En el año 1993, empezaron a llegar estos grupos en la sierra, y a medida que empezaron a ser más, comenzaron a ubicarse en nuestras tierras, nos empezaron a amenazar y haber desaparecidos porque muchos no querían dejar sus casas. Eso siguió así por mucho tiempo hasta que un día mataron a uno de mis hermanos y como las autoridades no hacían nada, nos tocó irnos (Sujeto 5).

Hace alrededor de 17 años, me toco irme del departamento del Choco, vivía en una zona rural cercana a Bellavista, donde ocurrió la masacre de Bojayá. Mi familia y yo nos sentimos amenazados de que algo así nos pudiera ocurrir a nosotros, tomamos la decisión de irnos, pues aquellos grupos nos presionaron en que lo mejor era desalojar la zona antes de que ocurriera algo peor. Prevención amigo (Sujeto 14).

Con relación a lo previamente descrito, a raíz del impacto desproporcionado que ha ocasionado el desplazamiento forzado en las comunidades negras y afrocolombianas, la Corte Constitucional ha decretado ordenes en las que determina responsables, acciones concretas y plazos con el propósito de mitigar el desplazamiento forzado de la población afrocolombiana, esto a través de la protección de sus derechos territoriales y a la atención continua de la población desplazada y confinada en los territorios (Rodríguez, 2010), entre esas órdenes se encuentran: "planes específicos de protección y atención con participación de las comunidades; plan de caracterización de territorios colectivos y ancestrales; puesta en marcha de la ruta étnica propuesta; estrategia de atención humanitaria para población afrocolombiana confinada y plan integral de prevención, protección y atención a la población afrocolombiana" (Ministerio del Interior, 2011, p. 16).

Sin embargo, los entrevistados al construir su relato revelaron que no han sido reparados aun a pesar de que algunos de estos han activado las rutas de atención integral, lo que permite concluir que las acciones de reparación que la corte describe, no han sido funcionales en los casos estudiados, lo que evidentemente dificulta la construcción de memoria histórica desde un sentido de resignificancia positiva. 
Con relación a la segunda subcategoría, huellas psicoafectivas, los entrevistados aludieron afectaciones significativas que estaban relacionadas con estrés postraumático, ansiedad y depresión (Bell, Méndez, Martínez, Palma \& Bosch, 2012; Defensoría del Pueblo, 2012), ideación suicida, ataques de pánico y consumo de sustancias psicoactivas (Alejo, Rueda, Ortega y Orozco, 2007), identificándose adicionalmente, la disminución de los niveles de calidad de vida, la ausencia de redes sociales de apoyo, la reestructuración de los roles familiares y el desarraigo cultural (Hewitt et al., 2015). En este apartado los entrevistados expresaron:

El dolor de dejar todo atrás, empezar de nuevo. De cero. Llegar a un lugar nuevo y saber que puedas ser rechazado. Vea, nosotros los afros nos ha tocado difícil desde siempre, y esta situación del conflicto lo ha empeorado todo, porque allá en el Choco hay muchos asentamientos de estos grupos, la pobreza nos ha golpeado fuerte y el olvido del gobierno es otro aspecto que no se evalúa (Sujeto 14).

Dejar el lugar donde crecí junto a mis seres queridos, fue duro, además la muerte de mi hermano por parte de los grupos paramilitares y migrar a la ciudad, sin saber hacer más nada que trabajar en el campo (Sujeto 5).

Lo anterior se sujeta a lo encontrado en la teoría, pues la experiencia de desplazamiento forzoso "genera sentimientos de vulnerabilidad, impotencia, desconfianza, culpa, vergüenza, resentimiento, pérdida de la identidad personal y del sentimiento de pertenencia, y falta de confianza en sí mismo para recuperar su proyecto de vida, negación de los derechos fundamentales económicos y sociales (los de trabajo, libertad, salud, educación y vivienda), discriminación y estigmatización)" (Hernández, 1999, pp. 2-3). A nivel psíquico produce temores, angustias e incertidumbre (los cuales se manifiestan con antelación al desplazamiento), la no posibilidad de procesar duelos durante el desplazamiento, en función a que conduce sus energías hacia la búsqueda de supervivencia, y por tanto imposibilita el satisfacer su necesidad de indemnización social, que a su vez le genera un sentimiento de venganza (Hernández, 1999).

La impronta que deja el conflicto armado en las víctimas se expresó en diferentes planos de la vida de los sujetos y sus familias, siendo los daños más referidos aquellos relacionados con las experiencias afectivas, los morales, los infligidos o revelados en sus lugares de arraigo y las afectaciones por perdida familiar y de su territorio. Con relación a lo anterior, se realizó una evaluación final de categoría verbal, permitiendo a los participantes expresar sus percepciones y expectativas individuales de como las actividades realizadas les pudieron permitir un apoyo en sus procesos de construcción de memoria histórica y por lo tanto de desarrollo de tejido comunitario, donde de manera general, aceptaron la importancia de participar en estos espacios, pues reconocieron que a partir de sus propios recursos comunitarios se pueden lograr muchas metas basadas en el bienestar social y de las familias afrocolombianas.

\section{Conclusiones}

Es importante señalar que a partir de la historia de Colombia las comunidades afrodescendientes, desde un apartado histórico, se han visto inmersas en confrontaciones armadas con vulneraciones sistemáticas y en consecuencia, han generado múltiples 
problemas sociales que transforman sus tradiciones y generan cambios forzosos en su tejido social y cultural.

Por lo tanto, a partir de análisis de los aspectos implicados en la recuperación de la memoria histórica de los habitantes del barrio Cristo Rey (Santa Marta, Colombia) se concluye que, a raíz del desplazamiento y despojo por parte de los grupos insurgentes, el tejido social de la comunidad afrocolombiana se encuentra deteriorado debido a la falta de políticas y estrategias sociales enfocadas a la reconstrucción de la memoria histórica. Muy a pesar del constante trabajo comunitario y de esfuerzo en preservar la unión de su cultura y raíces, aun se evidencia extrema revictimización y poco apoyo en resignificación de su proyecto de vida por parte del Estado.

Debido a la falta de espacios y ejercicios en el proceso de reconstrucción de memoria, no ha sido posible visibilizar la implementación de estrategias que fomenten su capital social. Por consiguiente, a través de la implementación del presente estudio, se realizaron procesos de colectivos y dinámicos desde la participación de la comunidad, para promover espacios de reconstrucción de la memoria histórica que permitan el desarrollo focalizado de tejido social, donde a partir de actividades de dialogo colectivo, grupos focales y mapas de rastreo e impacto, se buscó entrenar en el uso de estrategias de afrontamiento a las secuelas evidenciadas en el discurso de las familias participantes, a su vez apoyar en procesos de empoderamiento comunitario, ofreciendo ideas de sostenimiento y desarrollo psicosocial para la construcción de capital social.

Es entonces como con base a las propias percepciones de las familias participantes donde a partir de la evaluación final del proceso psicosocial realizado, se comparó su nivel de desarrollo del tejido social antes y después de las actividades de proyección histórica y social, permitiéndose concluir que la reconstrucción de la memoria histórica de la comunidad afrodescendiente, víctima del conflicto armado, del barrio de Cristo Rey (Santa Marta), si favorece el desarrollo de su tejido social.

\section{REFERENCIAS}

Alejo, E. G., Rueda, G., Ortega, M. y Orozco, L. C. (2007). Estudio epidemiológico del TEPT en población desplazada por la violencia política en Colombia. Universitas Psychologica, 6(3), 623-635. Disponible en https://revistas.javeriana.edu.co/index.php/revPsycho/ article/view/146

Bell, V., Méndez, F., Martínez, C., Palma, P. P. y Bosch, M. (2012). Characteristics of the Colombian armed conflict and the mental health of civilians living in active conflict zones. Journal Conflict and Health, 6(1), 1-8. https://oi.org/10.1186/1752-1505-6-10

Bernete, F. (2013). Análisis de contenido. En, A. L. Marín y A. Noboa (Coords.), Conocer lo social: estrategias y técnicas de construcción y análisis de datos (pp. 222-262). Madrid: Universidad Complutense de Madrid. Recuperado de http://alejandronoboa.uy/resources/files/others/librosypublicaciones/Libroconocerlosocial.pdf

Canal, M., Navarro, L. y Camargo, J. (2015). Comunicación, tejido social y trauma cultural: El caso de la población desplazada de Nueva Venecia en el departamento del Magdalena, Colombia. Verbum, 10(10), 25-47. Disponible en https://revistas.usergioarboleda. edu.co/index.php/verbum/article/view/465 
Centro de memoria, Paz y Reconciliación (s.f.). Centro de memoria, paz y reconciliación. [Online]. Disponible en http://centromemoria.gov.co

Echavarria, Y. e Hinestroza, L. (2016). Análisis del marco jurídico para la reparación colectiva a grupos étnicos en Colombia: caso comunidades negras del Chocó. Estudios de derecho, 73(161), 125-154. https://doi.org/10.17533/udea.esde.v73n161a07

Grueso, L. (2010). El papel de la memoria en la reconstrucción del sujeto colectivo de derechos. En, Alcaldía Mayor de Bogotá, Debates de la Memoria (pp. 201-208). Bogotá, D.C.: Centro de Memoria, Paz y Reconciliación. Recuperado de http://www.indepaz. org.co/wp-content/uploads/2018/08/Debates-de-la-Memoria.pdf

Hernández, E. (1999). El desplazamiento forzado y la oferta estatal para la atención de la población desplazada por la violencia en Colombia. Reflexión Política, 1(1), 1-11. Recuperado de https://revistas.unab.edu.co/index.php/reflexion/article/view/905

Hewitt, N., Juárez, F., Parada, A. J. P., Guerrero, J., Romero, Y., Salgado, A. y Vargas, M. (2016). Afectaciones psicológicas, estrategias de afrontamiento y niveles de resiliencia de adultos expuestos al conflicto armado en Colombia. Revista Colombiana de Psicologia, 25(1), 125-140. https://doi.org/10.15446/rcp.v25n1.49966

Jaramillo, J. (2010). La reconstrucción de la memoria histórica del conflicto colombiano en el actual proceso de Justicia y Paz. Alcances, desafíos y preguntas. Desafíos, 22(2), 31-70. Disponbile en https://revistas.urosario.edu.co/index.php/desafios/article/ view/1411

Lara, J., Enciso, L., Culma, C. y González, I. (2017). Recuperación de memoria histórica y sistematización de experiencias en el costurero de la memoria: Kilómetros de vida y de memoria. [Tesis de formación en investigación]. Universidad Católica de Colombia, Bogotá D.C, Colombia. Recuperado de https://repository.ucatolica.edu.co/bitstream/10983/15150/1/RECUPERACI\%C3\%93N\%20DE\%20LA\%20MEMORIA\%20 HIST\%C3\%93RICA\%20Y\%20SISTEMATIZACI\%C3\%93N\%20DE\%20EXPERIENCIAS.\%20COSTURERO\%20DE\%20LA\%20MEMORIA.pdf

Latorre, A. (2005). La investigación-acción. Conocer y cambiar la práctica educativa. Barcelona: Graó.

Lizarazo, N. (2014). Medidas de memoria para la construcción de paz, el caso del informe basta ya del centro de memoria histórica. [Tesis de especialización]. Universidad nacional de Colombia, Bogotá D.C, Colombia. Recuperado de http://www.bivipas.unal.edu. co/bitstream/10720/683/1/2567363_2014.pdf

Martínez, R. (2015). Memorias encadenadas al silencio: Disputas silenciadas para construir paz con la Diáspora Africana en Colombia. [Tesis de postgrado]. Universidad Nacional de Colombia, Bogotá, D.C., Colombia. Recuperado de http://www.bivipas.unal. edu.co/bitstream/123456789/718/1/TrabajoFinalRossihAmiraMartinez.pdf

Martínez-Salgado, C. (2012). El muestreo en investigación cualitativa. Principios básicos y algunas controversias. Ciência \& Saúde Coletiva. 17(3), 613-619. Disponible en http:// www.cienciaesaudecoletiva.com.br/artigos/el-muestreo-en-investigacion-cualitativaprincipios-basicos-y-algunas-controversias/9129

Mayan, M. (2001). Una introducción a los métodos cualitativos. [Módulo de entrenamiento para estudiantes y profesionales]. Alberta: International Institute for Qualitative Methodology. Recuperado de https://sites.ualberta.ca/ iiqm/pdfs/introduccion.pdf 
Monje, C. (2011). Metodología de la investigación cuantitativa y cualitativa. Neiva: Universidad Surcolombiana. Recuperado de https://www.uv.mx/rmipe/files/2017/02/Guiadidactica-metodologia-de-la-investigacion.pdf

Morales, P. (2018). Sanar la memoria, amanecer la palabra. Reflexiones sobre los procesos de memoria histórica desde las comunidades étnicas. Boletín Museo del Oro, (58), 189-206. Recuperado de https://publicaciones.banrepcultural.org/index.php/bmo/article/view/20785/21210

Otzen, T. y Manterola, C. (2017). Técnicas de muestro sobre una población a estudio. International Journal of Morphology, 35(1), 227-232. Disponible en http://www.intjmorphol.com/es/volumen/vol_1-es/

Prada, H. y Noreña, N. (2015). Subjetividades en comunidades afrocolombianas que han vivido la experiencia del desplazamiento forzado. [Trabajo de grado]. Fundación Universitaria Los Libertadores, Cartagena, Colombia. Disponible en http://hdl.handle. net/11371/367

República de Colombia. Defensoría del Pueblo. (2012). Protocolo de orientación y atención a víctimas de tortura y otros tratos crueles, inhumanos y degradantes en el marco del conflicto armado interno. [Online]. Recuperado de https://www.defensoria.gov.co/ public/pdf/04/pt_tortura.pdf

República de Colombia. Ministerio del Interior (2011). El enfoque diferencial para comunidades negras, afrocolombianas, raizales y palenqueras victimas del conflicto armado. Bogotá, D.C.: Mininterior. Recuperado de https://gapv.mininterior.gov.co/sites/default/ files/cartilla_enfoque_diferencial_afro_final_2.pdf

República de Colombia. Mininterior. (9 de diciembre de 2011). Por el cual se dictan medidas de asistencia, atención, reparación integral y de restitución de tierras a las víctimas pertenecientes a comunidades negras, afrocolombianas, raizales y palenqueras. [Decreto Ley 4635]. Diario Oficial No. 48.278.

Rodríguez, C. (2010). El desplazamiento forzado de los afrocolombianos: evaluación del cumplimiento del gobierno colombiano del Auto 005 de la Corte Constitucional. [Programa de Justicia Global y Derechos Humanos. Colección Justicia Global]. Bogotá. D.C.: Universidad de los Andes. Recuperado de http://www.odracial.org/files/r2_actividades_recursos/267.pdf

Rueda, J. (2013). Memoria histórica razonada. Una propuesta incluyente para las víctimas del conflicto armado interno colombiano. Historelo, 5(10), 15-52. https://doi. org/10.15446/historelo.v5n10.37088

San Martín, D. (2014). Teoría fundamentada y Atlas. Ti: recursos metodológicos para la investigación educativa. Revista electrónica de investigación educativa, 16(1), 104-122. Disponible en https://redie.uabc.mx/redie/article/view/727

Todorov, T. (2002). Los dilemas de la memoria. Un texto para valientes. Ponencia presentada en la Cátedra Julio Cortázar. Universidad de Guadalajara, México. Recuperado el 03 de agosto del 2018 en http://www.jcortazar.udg.mx/sites/default/files/TODOROV.pdf

Varguillas, C. (2006). El uso de Atlas. Ti y la creatividad del investigador en el análisis cualitativo de contenido upel. Instituto pedagógico rural el mácaro. Revista de educación, 12(2), 73-87. Recuperado de http://www.rinace.net/javier.murillo/Met_Inves_ Avan/Materiales/Varguillas.pdf 
Amparo Judith Echeverri Arias es Psicócloga, especialista en Gestión de procesos psicosociales. Con amplia experiencia con comunidades en condición de vulnerabilidad, trabajo social e investigativo. Actualmente trabajando en un programa social del ICBF y operado por la Universidad del Magdalena. https:/orcid.org/0000-0002-3505-8312

Michael Fabian Hernández Bolívar es Psicólogo, especialista en Gestión de procesos psicosociales de la Fundación Universitaria Claretiana. Con experiencia en el sector educativo desde el rol de directivo y orientador escolar, experiencia con comunidades en condición de vulnerabilidad, trabajo social e investigativo. https://orcid.org/0000-0003-4328-1693 